\title{
THERAPEUTICAL INFLUENCE OF BONE MARROW MESENCHYMAL STROMAL CELLS ON LOCAL SKIN RADIATION INJURIES IN RAT MODEL
}

\author{
Uzlenkova N. Ye., Skorobogatova N. G., Kryvko A. I.
}

\section{INTRODUCTION}

The skin is a barrier on the surface of the human body, which is easily damaged by ionising radiation. Skin radiation reactions play an important role in radiation accidents, but also as a limitation in radiotherapy of oncology patients. Up to $95 \%$ of all patients receiving radiation therapy show early or late skin reactions of varying intensity as radiotherapy affects not only the targeted tumor cells but also the surrounding healthy tissues ${ }^{1}$. The response of the skin to radiation exposure results a degree of skin damage (erythema, swelling, blisters, ulceration, necrosis and sclerosis) that depends on the radiation quality, the radiation dose and the depth of radiation penetration ${ }^{2}$. The most severe acute and late reactions mostly observed after accidental overexposure, are highly invalidating and necessitate a treatment, when exposed to radiation accidents, as well as during clinical radiation therapy ${ }^{3}$. At high doses of radiation, radiation damage of the skin usually takes a long time to heal, is characterized by repeated waves of inflammation at the irradiation site and recurrent episodes of necrotic ulcers with intense pain ${ }^{4}$. Current therapeutic strategies for treatment severe radiation injuries of the skin, especially chronic non-healing

\footnotetext{
${ }^{1}$ Ryan J.L. Ionizing radiation: the good, the bad, and the ugly. J. Investig. Dermatol. 2007. Vol. 132. P. 985-993. DOI 10.1038/jid.2011.411

Haubner F., Ohmann E., Pohl F.Wound healing after radiation therapy: review of the literature. Radiat. Oncol. 2012. Vol. 7. P. 162-189. DOI 10.1186/1748-717X-7-162

${ }^{2}$ Bray F. N., Simmons B. J., Wolfson A. H. Acute and chronic cutaneous reactions to ionizing radiation therapy. Dermatol. Ther. 2016. Vol. 15. P. 185-206. DOI 10.1007/s13555-016-0120-y

${ }^{3}$ Ohyama M. Hair follicle bulge: a fascinating reservoir of epithelial stem cells. J. Dermatol. Sci. 2007. Vol. 46. P. 81-89. DOI 10.1016/j.jdermsci.2006.12.002

Hill R.P., Rodemann H.P., Hendry J.H. Normal tissue radiobiology: from the laboratory to the clinic. Int J Radiat Oncol Biol Phys. 2001. Vol. 49, № 2. P. 353-365. DOI 10.1016/s0360-3016(00)01484-X

${ }^{4}$ Peter R. U. Cutaneous radiation syndrome in multiorgan failure. Br J Radiol Suppl. 2005. Vol. 27. P. 180-184. DOI 10.1259/bjr/56925969
} 
ulcers, are not completely satisfactory ${ }^{5}$. The concept of cell-based therapies of multipotent mesenchymal stromal cells (MSCs), isolated from bone marrow (BM) discussed for a number of years ${ }^{6}$. BM MSCs are a type of somatic stem cells with self-renewal, that are characterized by fibroblast-like morphology, high proliferation rate, attachment to cell culture plastic and form colonies, and the capacity to differentiate into multi-directional mesenchymal lineages ${ }^{7}$. In preclinical studies, MSCs have been shown to

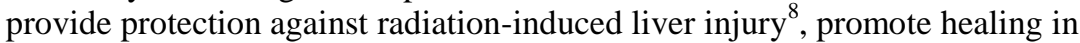
irradiated murine skin wounds, improve survival in irradiated mice ${ }^{9}$, mitigate the gastrointestinal syndrome in mice ${ }^{10}$, and restore the intestinal mucosal barrier in irradiated mice ${ }^{11}$.

Recent studies in animal models have confirmed that BM MSCs are effective for treatment of skin radiation damage ${ }^{12}$. Injected BM MSCs could

5 Peter R.U., Panizzon R.G., Seegenschmiedt M.H. Diagnosis and treatment of cutaneous radiation injuries. Radiation treatment and radiation reactions in dermatology. 2015. P. 185-188. DOI 10.1007/978-3-662-44826-7_15

${ }^{6}$ Liubavicuite A., Kaseta V., Vaitcuviene A. Regenerative potential of partially differentiated mesenchymal stromal cells in a mouse model of a full-thickness skin wound. EXCLI J. 2018. Vol. 17. P. 871-888. DOI 10.17179/excli2018-1504

Malhotra S., Hu M. S., Marshall C. D. Mesenchymal stromal cells-based therapeutics for wound healing. Stem Cells Int. 2016. DOI 10.1155/2016/4157934

7 Kolf C.M., Cho E., Tuan R.S. Mesenchymal stromal cells. Biology of adult mesenchymal stem cells: regulation of niche, self-renewal and differentiation. Arthritis Res Ther. 2007. Vol. 9, № 1. P. 204. DOI 10.1186/ar2116

Dominici M., Le Blanc K., Muller I. Minimal criteria for defining multipotent mesenchymal stromal cells. The International Society for Cellular Therapy. 2006. Vol. 8, № 4. P. 315-317.

${ }^{8}$ Francois S., Mouiseddine M., Allenet-Lepage B. Human mesenchymal stem cells provide protection against radiation-induced liver injury by antioxidative process, vasculature protection, hepatocyte differentiation, and trophic effects. Biomed Res Int. 2013. DOI $10.1155 / 2013 / 151679$

${ }^{9} \mathrm{Hu}$ K.X., Sun Q.Y., Guo M. The radiation protection and therapy effects of mesenchymal stem cells in mice with acute radiation injury. Br. J. Radiol. 2010. Vol. 83. P. 52-58. DOI 10.1259/bjr/61042310

${ }^{10}$ Saha S., Bhanja P., Kabarriti R. Bone marrow stromal cell transplantation mitigates radiation-induced gastrointestinal syndrome in mice. PLoS One. 2011. Vol. 6. P. 24072. DOI 10.1371/journal.pone.0024072

${ }^{11}$ Abdel-Mageed A. S., Senagore A. J., Pietryga D. W. Intravenous administration of mesenchymal stem cells genetically modified with extracellular superoxide dismutase improves survival in irradiated mice. BLOOD. 2009. VOL. 113, № 5. P. 1201-3. DOI 10.1182/BLOOD-2008-07-170936.

${ }^{12}$ Lataillade J.J., Douce C., Bey E. New approach to radiation burn treatment by dosimetry-guided surgery combined with autologous mesenchymal stem cell therapy. Regen. Med. 2007. Vol. 2. P. 785-794. 
give rise to functional skin cells and regenerate skin tissue ${ }^{13}$.The underlying mechanism of BM MSCs therapy of radiation damage to the skin remains unclear. It has been reported that BM MSCs could differentiate into myofibroblasts and play an important role in the formation of healthy tissues when combined with an occlusive dressing ${ }^{14}$. BM MSCs could become perifollicular cells, blood vessel cells or perisebaceous gland cells during the healing process. François et $\mathrm{al}^{15}$ found that human BM MSCs infused into irradiated immunodeficient NOD/SCID mice migrate towards the damaged skin and presence in the irradiated epidermis. Furthermore, in a skin defect model, human BM MSCs associated with fibroblast growth factor (FGF) differentiate into the epithelium and accelerate wound healing ${ }^{16}$. However, another study demonstrated that BM MSCs promote skin wound healing by paracrine mechanisms, such as the production of cytokines. Transforming growth factor (TGF) $-\beta 1$, stromal cell-derived factor (SDF) -1 and prostaglandin E2 (PGE2) are important factors involved in inflammatory and anti-inflammatory responses ${ }^{17}$. The results suggest that BM MSCs therapy may be a promising therapeutic approach to improve radiation-induced skin injures. The possible high clinical significance of the approach prompted us to focus our preclinical studies on BM MSCs. Setting of the problem and the aim of this study was to investigate the therapeutic influence of BM MSCs on the healing of acute skin radiation damage in rat model.

13 Eaton E.B., Varney T.R. Mesenchymal stem cell therapy for acute radiation syndrome: innovative medical approaches in military medicine. Mil. Med. Res. 2015. Vol. 2. P. 2-19. DOI 10.1186/s40779-014-0027-9

Nakagawa H., Akita S., Fukui M. Human mesenchymal stem ce lls successfully improve skin-substitute wound healing. Br J Dermatol. 2005. Vol. 153. P. 29-36. DOI 10.1111/j.1365-2133.2005.06554.x

${ }^{14}$ Kim J.-W., Lee J.-H., Lyo Y. S. The effects of topical mesenchymal stem cell transplantation in canine experimental cutaneous wounds. Vet. Dermatol. 2013. Vol. 24. P. 242-253. DOI 10.1111/vde.12011

${ }^{15}$ François S., Bensidhoum M., Mouiseddine M. Local irradiation induces not only homing of human Mesenchymal stem cells (hMSC) at exposed sites but promotes their widespread engraftment to multiple organs: a study of their quantitative distribution following irradiation damages. Stem Cells. 2005. Vol. 24, № 4, P. 1020-1029. DOI 10.1634/stemcells.2005-0260

${ }^{16}$ Epperly M.W., Guo H., Gretton J.E. Bone marrow origin of myofibroblasts in irradiation pulmonary fibrosis. Am J Respir Cell Mol Biol. 2003. Vol. 9. № 2. P. 213-224. DOI 10.1165/rcmb.2002-0069OC

${ }^{17}$ Rolfe K.J., Irvine L.M., Grobbelaar A.O. Differential gene expressionin response to transforming growth factor-beta 1 by fetal and posnata1 dermal fibroblasts. Wound Repair Regen. 2007. Vol 15. P. 897-906. DOI 10.1111/j.1524-475X.2007.00314.X 


\subsection{Animals}

\section{Materials and methods}

The white female rats weighing $160-180 \mathrm{~g}(\mathrm{n}=24)$ were uzed for this study. The animals were kept under pathogen free conditions in a standard diet. All experiments were conducted in accordance with the international principles of the European Convention on the Protection of Vertebrate Animals Used for Experiments and Other Scientific Purposes (Strasbourg, 1998) and biomedical standards in accordance with the Law of Ukraine "On the Protection of Animals from Cruelty" (Kyiv, 2006). The animal use protocol was reviewed and approved by the Institutional Bioethics Committee of the State Institution "IMR of NAMS of Ukraine" (Kharkov, Ukraine).

\subsection{Local irradiation}

The right hip skin of rats was local irradiated using the x-ray device Faxitron MultiRad 225 (manufactured by Faxitrin Bioptics LLC, USA) at dose rate of 7,2 $\mathrm{Gy} / \mathrm{min}$. The xray device has a programmable dosimeter, a motorized shelf for vertical height and distance control of the radiator in the range of $15 \mathrm{~cm}$ to $63 \mathrm{~cm}$, as well as a collimation system that allows you to change the beam parameters and the size of the radiation field with the focus of the beam in the center of the radiation field. The technical parameters of local irradiation was a voltage of an x-ray tube of $200 \mathrm{kV}$, a current of $9.5 \mathrm{~mA}$, the distance "source - object" $51 \mathrm{~cm}$, the irradiation area $(2,5 \times 2,5)$ $\mathrm{cm}$. Local irradiation was carried out in different conditions: 1 - without filters; 2 - using a filter $0.5 \mathrm{~mm} \mathrm{Al} ; 3$ - using a filter $0.3 \mathrm{~mm} \mathrm{Cu}$. To facilitate the observations, the hairs of the legs were removed $24 \mathrm{~h}$ before local irradiation.

\subsection{Clinical score of skin radiation damage}

After local irradiation, the damaged skin of each rat was scored according to skin reaction criteria of the International Union Against Cancer.

The frequency, latency period and healing of acute skin radiation injuries was evaluated by scoring scale (in conventional units): 0 - normal (the skin shows no change); 1 - the skin shows obvious erythema (1,0-1,5 units); 2 - the skin shows dry desquamation reactions (2,0-2,5 units); 3 - the skin shows confluent moist desquamation reactions and edema (3,0-3,5 units); 4 - the skin shows bleeding erosion and ulceration (4,0-4,5 units.); 5 - the skin shows of ischemic dermal necrosis (5,0 units).

The severity of radiation skin damage of each rat was monitored every day for a total of 180 days after exposure.

\subsection{Isolation of rat BM cells}

BM cell suspensions were obtained from femurs of unirradiated animals under aseptic conditions by flushing the marrow cavity with physiological saline and centrifuged at $300 \mathrm{~g}$ for $10 \mathrm{~min}$. 


\subsection{Culturing and expansion ex vivo of rat BM MSCs}

BM cells were seeded into medium: $\alpha$ MEM supplemented with $2 \mathrm{mM}$ L-glutamine (Biowest, France), 15\% fetal bovine serum (FBS; Biowest, France), $50 \mathrm{U} / \mathrm{ml}$ penicillin (Sigma-Aldrich) and $50 \mu \mathrm{g} / \mathrm{ml}$ streptomycin. The cultures were incubated at $37^{\circ} \mathrm{C}$ in $5 \% \mathrm{CO}_{2}$ atmosphere at absolute humidity. After 3 days, non-adherent cells were removed and the culture medium was replaced. The medium was replaced every three days. When the cells grew to about $80 \%$ confluence of monolayer, they were subcultivated for 2 passages. After the 2-nd passage BM MSCs were harvested for cryopreservation.

\subsection{Cryopreservation of rat BM MSCs}

The cultured MSCs (passage 2) were mixed with the medium $\alpha$ MEM supplemented with $15 \%$ FBS and cryoprotectant dimethyl sulfoxide (DMSO) (neoFroxx GmbH, Germany) of final concentration 10\%. The cells were removed into cryotubes (Nunc) and were put into container Nalgene Mr Frosty Crryo $1{ }^{\circ} \mathrm{C}$ Freezing (Thermo Scientific, USA). The container was placed in the freezing camera at $\mathrm{T}=-70^{\circ} \mathrm{C}$. Under the selected conditions, cryopreservation provided a slow cooling of BM MSCs with a rate $1{ }^{\circ} \mathrm{C} / \mathrm{min}$ to $=-70^{\circ} \mathrm{C}$ and long-term storage of cultured cells at a constant temperature $\mathrm{T}=-70^{\circ} \mathrm{C}$ was for 6 months before use in an in vivo experiment with local exposure.

\subsection{Thawing BM MSCs and removal of DMSO}

The samples of cryopreserved cell suspensions was put into a water bath at $+37^{\circ} \mathrm{C}$ for thawing. Then a removal of DMSO was performed by slow dilution of cryopreserved cell suspensions of BM MSCs with Hanks solution in the appropriate volume ratio of $1: 5$. After centrifugation at $300 \mathrm{~g} / \mathrm{min}$ for $10 \mathrm{~min}$, the cell pellet was mixed with the required volume of physiological solution for using in the injections in a rat model.

\subsection{Counting the total cell number}

Counting the total cell number was carried out in the Goryaev chamber by the standard method.

\subsection{Adipogenic differentiation of rat BM MSCs}

Induction of adipogenic differentiation of cryopreserved BM MSCs were carried out using culture medium aMEM (Biowest, France) supplemented with $2 \mathrm{mM}$ glutamine (Biowest, France ), 0,5 mM isobutylmethylxanthine (Sigma, USA), $10 \mu \mathrm{g} / \mathrm{ml}$ insulin (Sigma, USA), $200 \mu \mathrm{M}$ indomethacin (Sigma, USA), $1 \mu \mathrm{M}$ dexamethasone (Sigma, USA), $10 \%$ FBS (Biowest, France). The culture medium was changed twice a week. After ending of the cultivation the cells were fixed with calcium formol mixture for $30 \mathrm{~min}$ at temperature $\mathrm{T}=+4^{\circ} \mathrm{C}$ and stained with Oil $\mathrm{Red} \mathrm{O}$ at room temperature. 


\subsection{BM MSCs injections in rat model}

After local irradiation, rats were randomly divided into two groups: control group and BM MSCs - injected group. Each rat in the BM MSCs injected group received local multipoint injection of 1,5 $\times 10^{6} \mathrm{BM}$ MSCs around the damaged skin twice at days 14 and 21 after irradiation. Rats in the control group received a local injection of $1 \mathrm{ml}$ physiological saline.

\subsection{Wound size measurement}

The size of the injured skin area was measured by planimetry (in millimeter) and photos were taken in the dynamics of radiation lesion development up to 180 days after irradiation.

\subsection{Statistical analysis}

All statistical procedures were performed using BIOSTAT v 4.03 statistical software. Data were presented as the mean \pm standard deviation. Comparisons between two groups were conducted using the Fisher method. $\mathrm{P}<0.05$ was considered to indicate a statistically significant difference.

\section{Results}

\subsection{Quantitative characteristics of cultured BM MSC expanded ex vivo}

MSCs isolated from BM are able to adhesion and proliferation on culture plastic. At a low seeding dose clonogenic MSCs form fibroblast-like colonies in monolayer culture. During expansion ex vivo clonogenic MSCs give a rise to new subpopulations of MSCs which can be multiplied multiple times under monolayer culture conditions. This makes it possible to obtain the required amount of BM MSCs intended for experimental and clinical application.

According to the results obtained in our investigation, at seeding cell dose $10^{5}$ myelocaryocytes $/ \mathrm{cm}^{2}$ rat clonogenic BM MSCs formed colonies which were consisted of spindle-shaped them, triangular and elongated fibroblast-like cells. MSC colonies located separately from each other and were different in the size. At day 14 of cultivation it was determined that on average 7 MSC colonies per $10^{6}$ seeded myelocaryocytes were present in the primary BM culture.

It was possible to distinguish 3 types of BM MSC colonies - small colonies that included 40-50 MSCs, medium ones, which consisted of 50-100 MSCs and large colonies with more than 100 MSCs, some large colonies reaching $0,5 \mathrm{~mm}$ in diameter. The differences in the size of the colonies testified to the heterogeneity of the pool of the clonogenic BM MSCs. Clonogenic BM MSCs with higher proliferative potential form large colonies (fig. 1). These clonogenic MSCs are candidates for the role of the stem compartment of the BM MSC pool. 
Such a small population of early stromal progenitors was successfully propagated under the culture conditions in the experiment.

At the initial stage of expansion (at seeding dose of $10^{4}$ myelocaryocytes per $\mathrm{cm}^{2}$ ), rat clonogenic BM MSCs gave a new generation of MSCs, which continued to proliferate and increased their numbers to $2,0 \times 10^{5}-3,0 \times 10^{6}$ MSCs for 10-12 days in primury culture. Expansion ex vivo of BM MSCs was performed for 2 passages over 3 weeks of cultivation. BM MSCs were reseeded at $80 \%$ confluence.

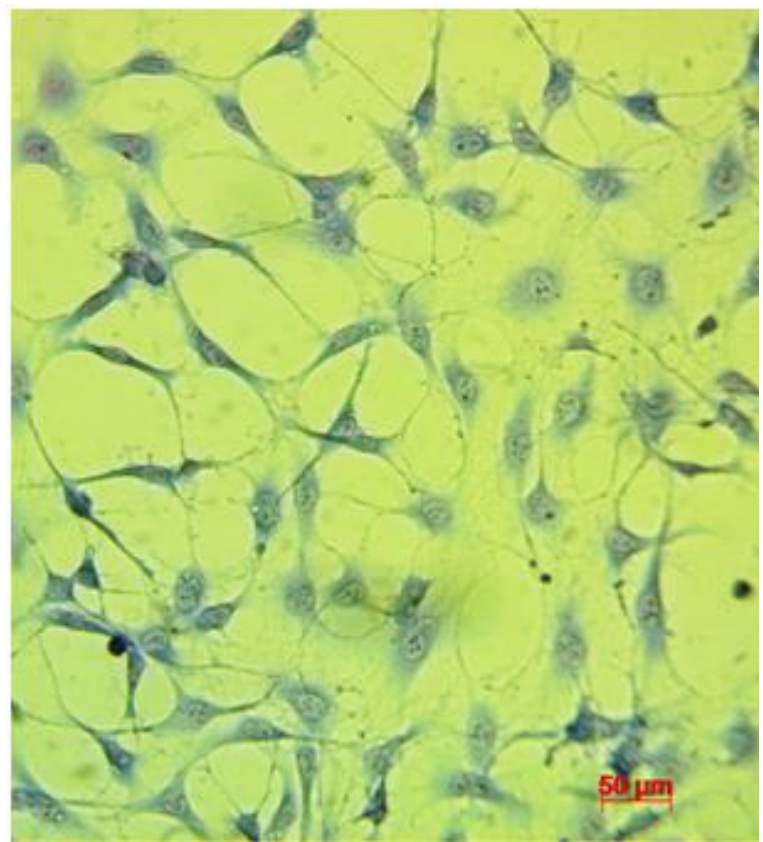

Fig. 1. Fragment of rat BM MSC colony in primary culture at day 14

To evaluate the effectiveness of the selected expansion protocol, it was performed a quantitative assessment of the obtained BM MSCs cultures. Because the BM MSCs pool is heterogeneous and proliferating, there was calculate a coefficient of increase in cell number (CICN). CINC was determined after subculturing as the ratio of the number of obtained BM MSCs (n2) to the number of seeded BM MSCs (n1), namely: CINC $=\mathrm{n} 2 / \mathrm{n} 1$. According to the CINC, the multiplicity of BM MSCs number increase after subcultivation was evaluated. In our study the CINC for cultures of BM MSCs was 4,02 $\pm 0,76$ (passage 1) and 3,24 $\pm 0,73$ (passage 2). 
The cultivated BM MSCs were also characterized by calculation of population doubling level (PDL), which reflected the number of the BM MSCs doubles at each stage of cultivation (passage 1,2). In obtained results PDL did not exceed 2 and was 1,79 $\pm 0,26$ (passage 1) and 1,64 $\pm 0,29$ (passage 2), so it was almost at the same level at each stage of the subculturing. The cumulative PDL was $3,14 \pm 0,38$ which indicated that proliferative potential of the BM MSCs population was maintained during expansion ex vivo for 2 passages. Thus, our results demonstrated that selected methodological approaches of cultivation provided stable conditions for the shirt-term expansion of rat BM MSCs intended for therapeutic injection in an in vivo experiment.

\subsection{Functional characteristics of rat BM MSCs after cryopreservation}

Due to the need for long-term storage of the cultured BM MSCs, cryopreservation of the cell samples under 10\% DMSO protection was worked out. After thawing and 10\% DMSO removal $(97,6 \pm 1,2) \%$ of BM MSCs were preserved.

Before use, the viability of cryopreserved BM MSCs was characterized by calculation the number of apoptotic cells in the thawed suspensions under fluorescence microscopy by Acridine Orange (AO) binding.

In each batch of cryopreserved BM MSCs suspensions 150-200 cells were counted and the percentage of the cells with typical signs of apoptosis was calculated: 1 - viable cells in which AO causes diffuse green fluorescence; 2 - cells in the initial stage of apoptosis with condensation of the chromatin.

According to the obtained data in the thawed samples of BM MSCs suspensions $(n=21)$, there were practically only viable cells, the number of which reached $(80,8 \pm 3,4) \%$ and the level of cells with morphological signs of apoptosis did not exceed $(19,2 \pm 1,6) \%$. After cryopreservation among the viable cells there were the cells with destabilized plasmatic membranes. The fluorescence staining cryopreserved BM MSCs with AO was detected under fluorescence microscopy (Fig. 2).

In our special studies, the functional characteristics of BM MSCs were examined after cryopreservation. After thawing and removal of the DMSO, each batch of the BM MSCs was analyzed in: 1) evaluation of the clonogenic and proliferative ability; 2) assessment specific ability to induce adipogenic differentiation.

After explantation into aMEM supplemented with 15-20\% FBS at a different seeding cell doses from 70 to $10000 / \mathrm{cm}^{2}$, cryopreserved BM MSCs adhered to plastic and proliferated in culture. At seeding cell dose $70 / \mathrm{cm}^{2}$ a growth of discrete BM MSCs colonies of different sizes was observed on day 14 of cultivation (Fig. 3). 


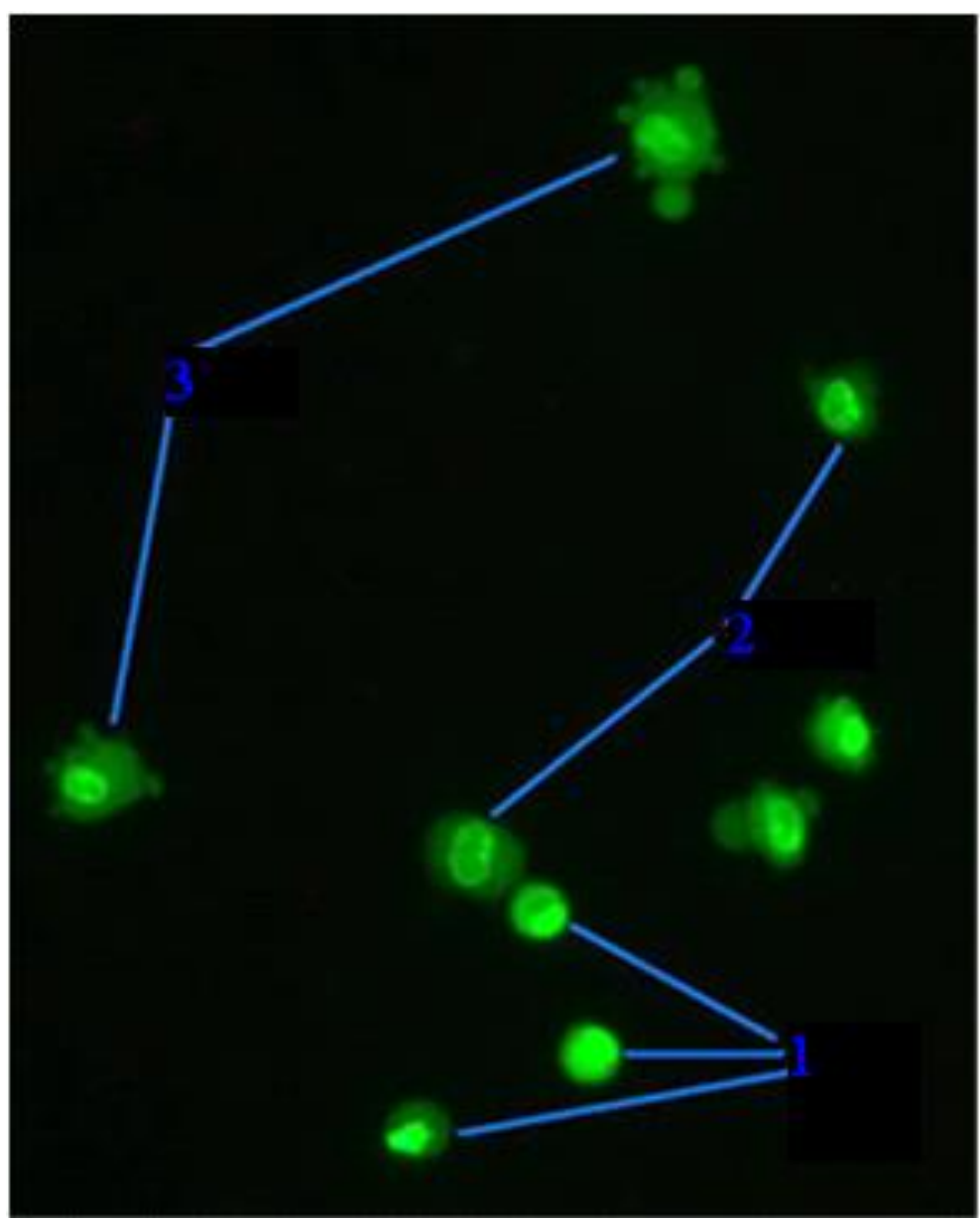

Fig. 2. Cryopreserved/thawed BM MSCs of rats. 1 - viable cells, 2 - premembrane chromatin condensation (early stage of apoptosis), 3 -viable cells with destabilized plasma membranes. Fluorescence microscopy, $\times 350$

At seeding cell dose $10000 / \mathrm{cm}^{2}$ BM MSCs culture was $70 \%$ of confluence on day 4 , and $90 \%$ of confluence on day 6 . Such proliferative activity was confirmed at the control level of BM MSCs cultures without cryopreservation. As demonstrated our results the BM MSCs population have been expanded without loss of their clonogenic and proliferative abilities after cryopreservation and low-temperature storage. 


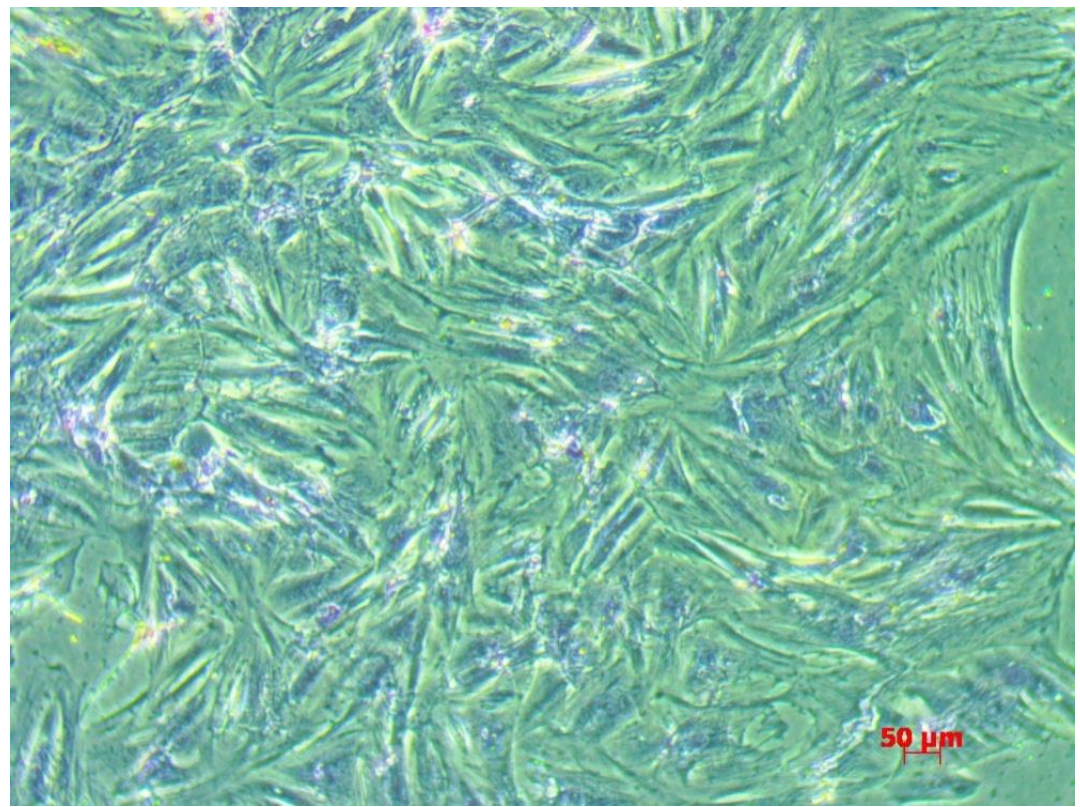

Fig. 3. Fragment of BM MSC colony obtained from the cryopreserved sample of expanded BM MSCs (passage 2)

Assessment of adipogenic differentiation ability of cryopreserved BM MSCs were carried out in adipo-induced condition using aMEM medium supplemented with $2 \mathrm{mM}$ glutamine, 0,5 $\mathrm{Mm}$ isobutylmethylxanthine, $10 \mu \mathrm{g} / \mathrm{ml}$ insulin, $200 \mu \mathrm{M}$ indomethacin, $1 \mu \mathrm{M}$ dexamethasone, $10 \%$ FBS.

Cryopreserved BM MSCs grown in adipogenic medium at day 7 presented the appearance of cells with adipocyte morphology. The differentiating cells were arranged in a small groups and had vacuoles with neutral lipids positively stained with Oil Red O (Fig. 4). Spontaneous adipogenic differentiation of the studied cells did not occur. These results suggest that in cryopreserved samples are present early candidates for the BM MSC population, which are save their differentiation capacities, in particular in the adipogenic direction.

Thus, in our study, it was confirmed that cryopreserved BM MSCs (passage 2) save their functional abilities as proliferative and differentiating potentials and can be used for further therapeutic injection in the rat model of acute radiation skin injuries. 


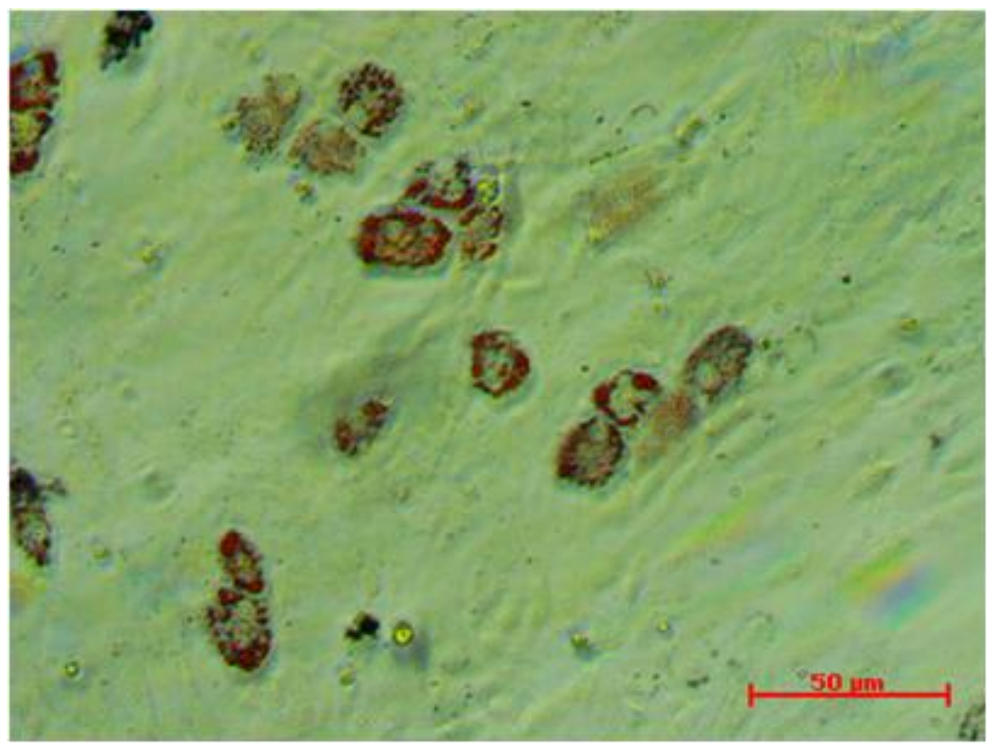

Fig. 4. Adipogenic differentiation of cryopreserved BM MSC of rat in culture. Staining with Oil Red O

\subsection{Establishment of rat model of skin radiation damage}

The results of studies of local $\mathrm{x}$-ray irradiation of the thigh of rats with a single dose of 50 Gy showed acute radiation damage to the skin with the development of specific clinical reactions. It was found that acute radiation damage to the skin was presented as a progression from primary erythema (hyperemia 1.0 units at 12-24 hours) to dry desquamation, wet desquamation and ulceration.

The latent period was observed for 7-9 days after exposure, when no visual changes were detected in irradiation area. At day 10 true erythema reaction (hyperemia of 1,5 units) was detected and then manifestations of dry desquamation (epitheliitis) with peeling and appearance of yellow crusts was developed. In the subsequent periods, at days 15-21, dry epitheliitis (2,0-2,5 units) turned into moist desquamation (3,0-3,5 unit).

Then, at days 21-28 after exposure the reaction of moist desquamation, which characterizes acute radiation damage in irradiated skin, were observed in $100 \%$ rats of control (untreated) group.

In the rat model of radiation skin damage under different $\mathrm{x}$-ray conditions of exposure (without filters or with using $0,3 \mathrm{~mm} \mathrm{Cu}$ filters and $0,5 \mathrm{~mm} \mathrm{Al}$ filters) were established the severe lesions depending on the permeability of radiation. 
The most severe radiation damage to the skin were observed in $(55,6 \pm 4,1) \%$ of rats irradiated at a single dose of 50 Gy using a $0,3 \mathrm{~mm} \mathrm{Cu}$ filter (the most permeability of radiation of the above).

In this rat model of local irradiation progressed to skin ulceration were occurred in $(22,2 \pm 1,7) \%$ of rats already at day 45 after exposure. The severe radiation damage to the skin was chronic with individual features. The chronic ulcers $(4,0-4,5$ unit) were identified in $(16,7 \pm 1,9) \%$ of rats which were spread to deeply located layers of adjacent tissues and not heal for a long time at days 145 of observations.

In local irradiation with using a $0,5 \mathrm{~mm} \mathrm{Al}$ filters the degree of radiation damage to the skin was lower and superficial. The differences concerned the depth of the radiation penetration and lesions were less deeply located in irradiated skin layers. At the recovery stage, this contributed to a more complete healing of the irradiated skin areas in a short time.

Thus, in our study a rat model of local irradiation was established. It was demonstrated that the local irradiation at a single dose of 50 Gy with using a $0,3 \mathrm{~mm} \mathrm{Cu}$ filter was optimal rat model to simulate acute reactions and chronic ulcerative processes in the irradiated skin, which makes the prospect of our further research of therapeutic influence of rat BM MSCs.

\subsection{Clinical score and healing of skin radiation damage under the therapeutic injection of $B M M S C s$}

The clinical score in rat model of skin injuries following local irradiation of the thigh of rats at single dose $50 \mathrm{~Gy}$ with using a $0,3 \mathrm{~mm} \mathrm{Cu}$ filter showed acute radiation damage in control (untreated) group.

In control group specific clinical reactions at day 14 after exposure were presented with depilation, swelling, mild erosion and slight seepage in irradiated skin.

At day 21 the wounded skin was erosive with red edema, erosion and moist areas of seepage, which further formed into ulcers (fig. 5 a,b).

The severe injury to the rats skin in control group was presented evidenced ulceration at day 45 after irradiation (fig. 6).

In our study the therapeutic using of expanded ex vivo BM MSCs were performed as a local multipoint injection around the damaged skin area subcutaneously at a range of $1,5 \times 10^{6}$ cells per animal twice in the acute period, at days 14 and 21 days after exposure.

As shown the obtained results, the rat irradiated skin in BM MSCsinjected group was less injured when compared to the control (untreated) group. As shown the obtained results, the rat irradiated skin in BM MSCsinjected group was less injured when compared to the control (untreated) group. At acute period there were no observed inflammatory reactions and redness in irradiated skin at day 15 after exposure (i.e 2 day after the first BM MSCs injection) (Fig. 7 a,b). 


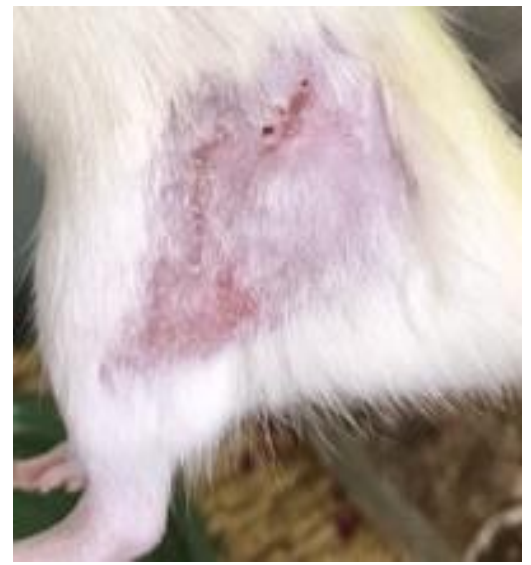

a

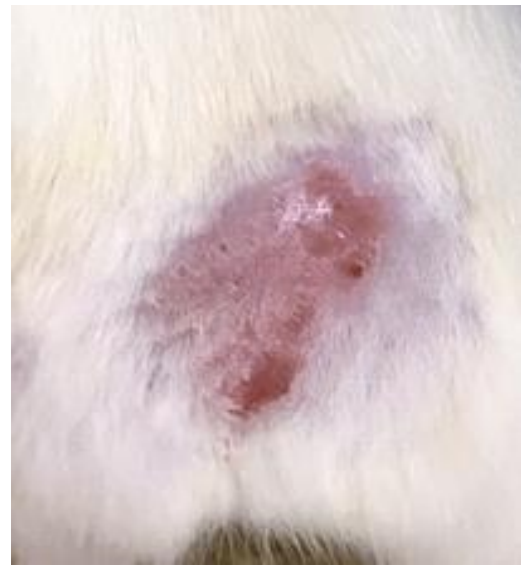

$\mathrm{b}$

Fig. 5. Skin radiation damage in rats following local 50 Gy x-ray irradiation. Control (untreated) rats showed a severe injury to the skin. (a) 14 day after exposure; (b) 21 day after exposure

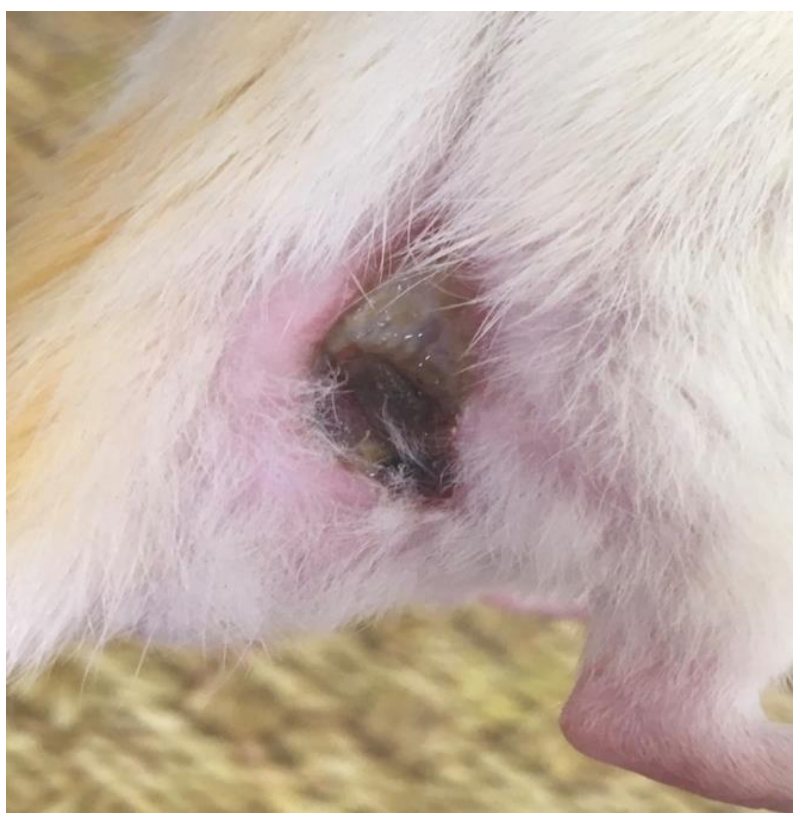

Fig. 6. Skin radiation ulceration in rats following $50 \mathrm{~Gy}$ x-ray irradiation (progressed up day 45 after exposure) 


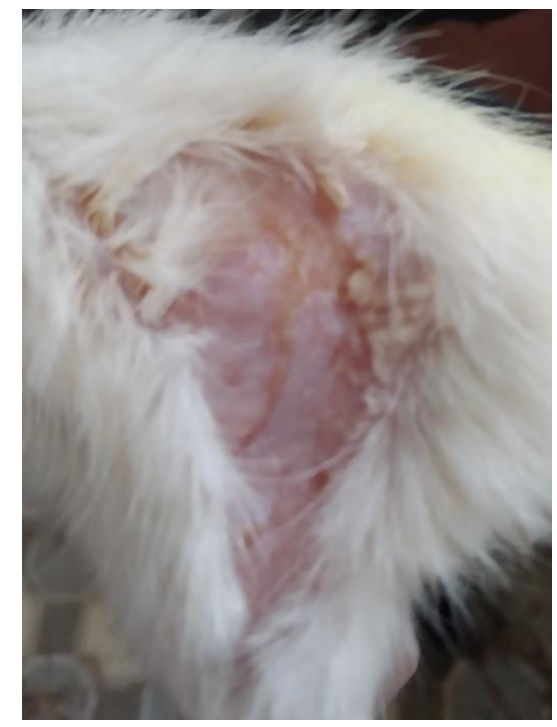

a

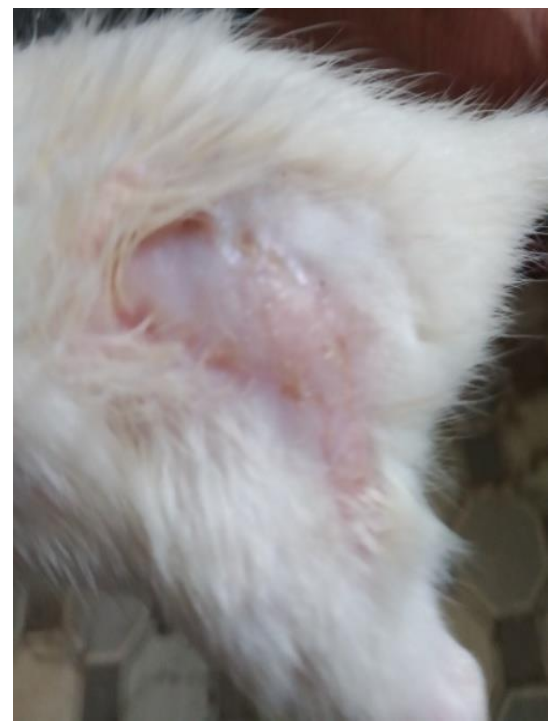

b

Fig. 7. The irradiated skin in rats of BM MSCs-injected group was less injured when compared to the control group. (a) control group before BM MSCs injection (15 day after exposure); (b) BM MSCs-injected group (2 day after the first BM MSCs injection)

At the same time in BM MSCs-injected group the development of skin radiation lesions were delayed and limited by the appearance of yellow crusts without pronounced inflammatory reactions in contrast to the control (untreated) group.

Thus, the scabs in skin irradiated area were thinner, lighter and superficial at day 22 after exposure (i.e 7 day after the first and 2 day after the second BM MSCs injection) (Fig. 8 a,b).

In BM MSCs-injected group the acute radiation skin damage were limited only moist desquamation, were not evolving to ulceration compared to the control (untreated) group and healed with time at a faster rate at day 36 after irradiation (i.e 28 day after the first and 21 day after the second BM MSCs injection) (Fig. 9 a,b).

The lesions in irradiated skin of rats in BM MSCs-injected group were not evolving to ulceration and displayed an important healing at days 45 exposure compared to the control (untreated) group (Fig. $10 \mathrm{a}, \mathrm{b}$ ). 


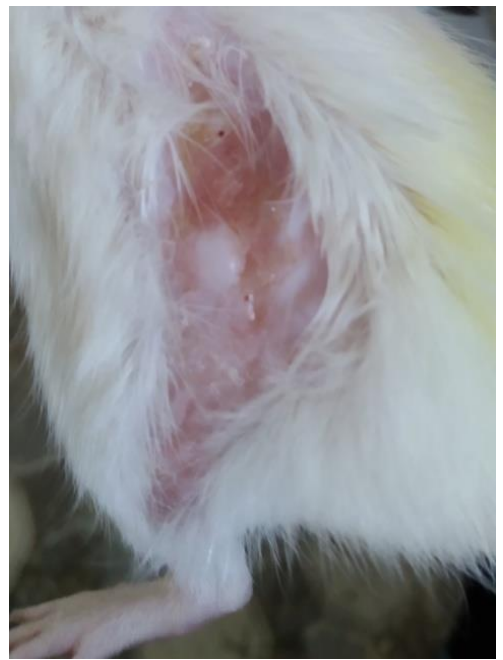

a

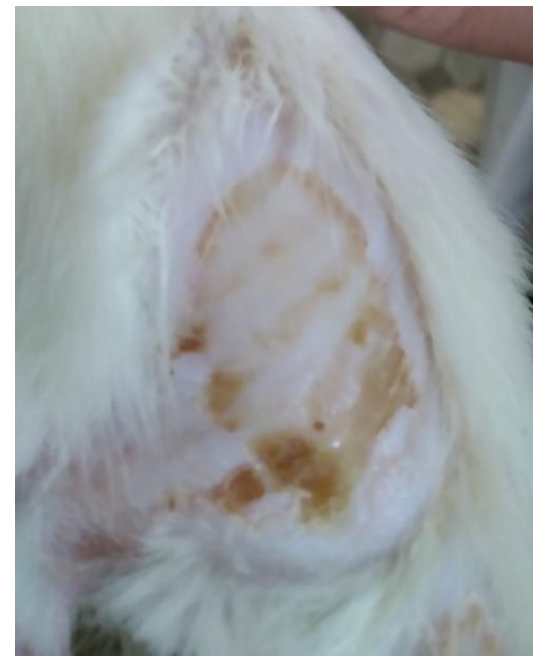

6

Fig. 8. The development of skin radiation lesions in rats of BM MSCsinjected group were delayed compared to the control (untreated) group. (a) control group (22 day after exposure); (b) BM MSCs-injected group

(7 and 2 days after twice BM MSCs injection)

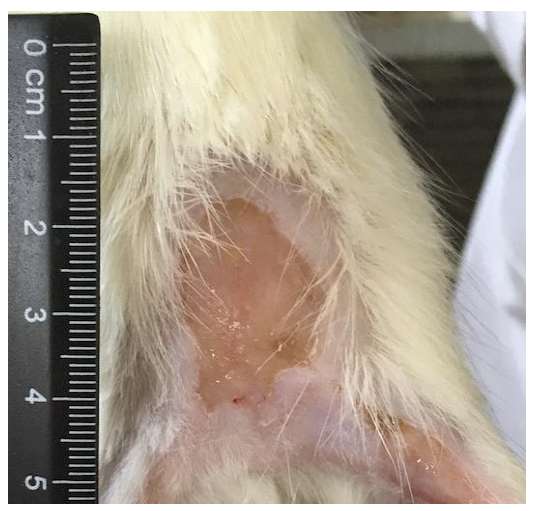

a

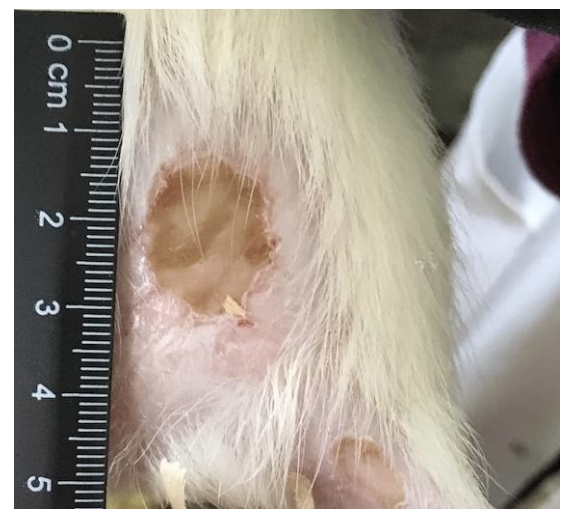

b

Fig. 9. The irradiated skin in rats of BM MSCs-injected group displayed a faster healing compared to the control group. (a) control group

(36 day after exposure); (b) BM MSCs-injected group

(28 and 21 days after twice BM MSCs injection) 


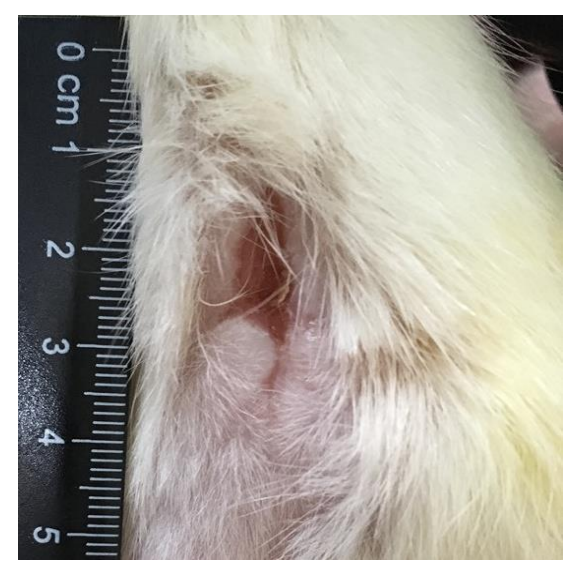

a

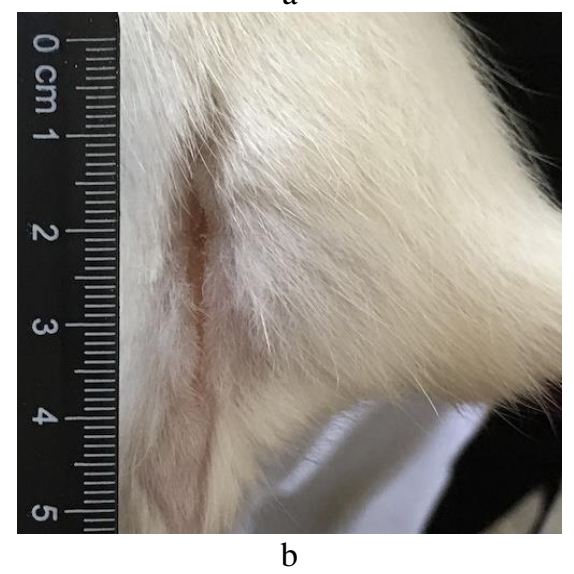

Fig. 10. The irradiated skin in rats of BM MSCs-injected group was an important healing compared to the control group. (a) control group (45 day after exposure); (b) BM MSCs-injected group (37 and 30 days after twice BM MSCs injection)

The clinical score analysis was confirmed that the rat skin radiation damage in BM MSCs-injected group were less and demonstrated an accelerated healing. Improved clinical scores in BM MSCs-injected rats for the studied skin parameters of degree of radiation lesions were significantly 1,3 times lower $(\mathrm{p}=0,017)$ compared to control (untreated) rats starting at day 29 and up to day 45 after exposure (Fig. 11). 


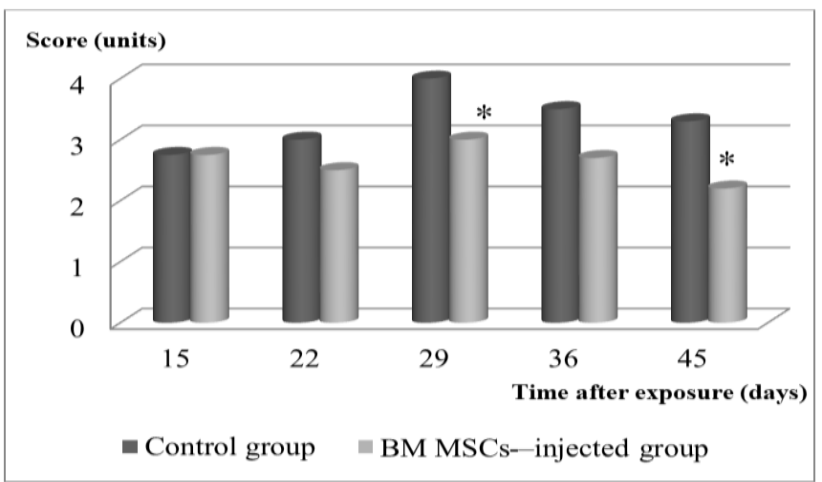

Fig. 11. Scores of irradiated skin in BM MSCs--injected rats (white histograms) were significantly improved when compared to control rats scores (shaded histograms). Data are presented as the mean \pm SEM, $\mathrm{n}=12$ for each group $(* \mathrm{p}<0,05$ vs control; NS not significant)

\subsection{The wound size measurement in skin radiation damage under} the therapeutic injection of BM MSCs

In our study the wounds size in irradiated skin of rats in BM MSCsinjected group was measured and compared to control (untreated) group. At day 15 after exposure (i.e 2nd day after the first BM MSCs injection) the wound size in irradiated skin did not differ in BM MSCs-injected and control groups and was respectively $(63 \pm 4) \mathrm{mm}^{2}$ and $(68 \pm 6) \mathrm{mm}^{2}$.

At day 22 after exposure (i.e 2 and 7 days after twice BM MSCs injection) irradiation damage areas of skin in BM MSCs-injected rats practically did not change in size $(60 \pm 3) \mathrm{mm}^{2}$ and increased to $(80 \pm 4) \mathrm{mm}^{2}$ in control rats.

In contrast the rats in control group, the irradiated skin in BM MSCs injection group experienced more intensive 1,5 times wound healing $(\mathrm{p}=0,034)$ starting from the day 29 after exposure (i.e 15 and 7 days after twice BM MSCs injection) by wound size was of $(58 \pm 4) \mathrm{mm}^{2}$ compared to $(86 \pm 7) \mathrm{mm}^{2}$.

In the following time up to days 36 and 45 after exposure the wound size in irradiated skin of BM MSCs-injected rats consistently decreased respectively to $(37 \pm 3) \mathrm{mm}^{2}$ and $(29 \pm 2) \mathrm{mm}^{2}$ compared to $(72 \pm 4) \mathrm{mm}^{2}$ and $(56 \pm 3) \mathrm{mm}^{2}$ in control (untreated) rats. The improve parameters of the wound size reducing 1,7 times $(\mathrm{p} \leq 0.001)$ and 1,9 times $(\mathrm{p} \leq 0.001)$ display a faster and more complete healing of skin radiation damage in rats with twice injected of BM MSCs (Fig. 12). 
Thus, our results performed that the therapeutic using of expanded ex vivo BM MSCs as a local multipoint injection around the damaged skin area at a range of $1,5 \times 10^{6}$ cells per animal twice at days 14 and 21 after single dose 50 Gy irradiation had a significant therapeutic effect. There was determined the reduction of local inflammatory response in irradiated skin areas at days 2 and 7 after twice BM MSCs injection, mitigation on 1,3 times the score of skin radiation damage, accelerated healing and decreased on 1,7 and 1,9 times the wound size at days 37 and 30 after twice BM MSCs injection.

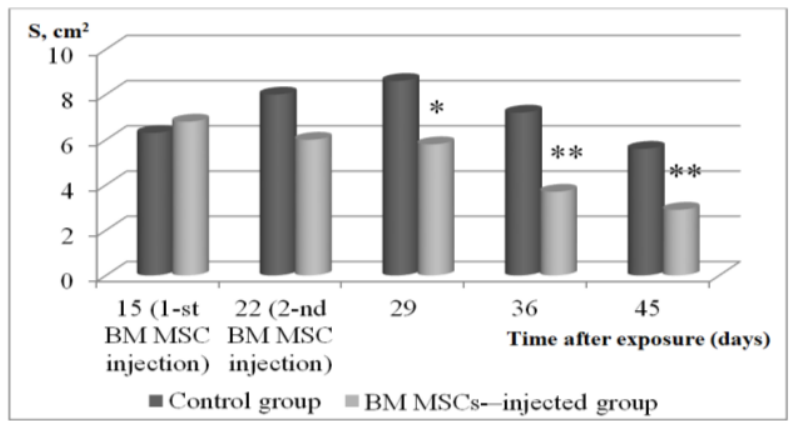

Fig. 12. The wound size in irradiated skin measured in BM MSCsinjected rats (white histograms) were significantly improved when compared to control rats (shaded histograms). Data are presented as the mean \pm SEM, $n=12$ for each group $(* p<0,05, * * p<0,001$ vs control; NS not significant)

\section{Discussion}

In our study the acute skin radiation damage in rat model were treated with local injection of expanded ex vivo BM MSCs and it was demonstrated that BM MSCs had protective effects. BM MSCs not only had anti - inflammatory effect, but also reduced the severe of injury and promoted healing of acute skin radiation damage in a rat model. According to our results, the inflammatory reaction were significantly reduced, the radiation lesions in skin were not evolving to ulceration and displayed more faster and an important healing at day 45 after BM MSCs injection. The clinical score was significantly 1,3 time milder and the depth and wound size in irradiation area in the BM MSCs group was on 1,7 and 1,9 times decreasing than in the control group. These results indicating therapeutic effect of BM MSCs on radiation skin damage.

It is reported that the radiation skin damage are difficult to heal because of the local vascular injury leads to micro-circulation disturbance and tissue 
collagen fiber damage ${ }^{18}$. Agay et $\mathrm{al}^{19}$ established a minipigs model and found that the application of MSCs can significantly reduce the extent of radiation injury result in lymphocyte infiltration and angiogenesis in the dermis and subcutaneous tissue.

Deng et al. ${ }^{20}$ treated C57BL/6 mice receiving a lethal dose of irradiation with fluorescence-labeled BM MSCs and found that donor BM MSCs migrated to the skin and converted into skin cells, so as to regenerate skin tissue. Moroz et al. ${ }^{21}$ also demonstrated that the implanted BM MSCs migrated to the damaged skin and subcutaneous injection of BM MSCs surrounding the damaged skin at 8 days after irradiation accelerated the healing of skin ulcers. It is also reported that treatment with BM MSCs can enhance the growth of hair in mice with radioactivity-induced injuries ${ }^{22}$.

MSCs are characterized by their potential for self-renewal and multidirectional differentiation, migrating towards damaged tissues to exert a reparative role and secrete a variety of growth factors. A large body of studies has shown that MSCs are involved in tissue repair in intestinal injury caused by radiation $^{23}$, lung injury ${ }^{24}$, salivary gland damage ${ }^{25}$ and combined

${ }^{18}$ Millar W. T., Van Den Aardweg G. J., Hopewell J. W. Repair kinetics in pig epidermis: An analysis based on two separate rates of repair. Int J Radiat Biol. 1996. Vol. 69. P. 123-140. DOI 10.1080/095530096146255

${ }^{19}$ Agay D., Scherthan H., Forcheron F. Multipotent mesenchymal stem cell grafting to treat cutaneous radiation syndrome: Development of a new minipig model. Exp Hematol. 2010. Vol 38. P. 945-956. DOI 10.1016/j.exphem.2010.06.008

${ }^{20}$ Deng W., Han Q., Liao L. Engrafted bone marrow-derived flk- (1+) mesenchymal stem cells regenerate skin tissue. Tissue Eng. 2005. Vol 11. P. 110-119. DOI 10.1089/ten.2005.11.110

${ }^{21}$ Moroz B. B., Onizhshenko N. A., Lebedev V. G. The influence of multi-potent mesenchymal stromal cells of bone marrow on process of local radiation injury in rats after local beta-irradiation. Radiats Biol Radioecol. 2009. Vol. 49. P. 688-693.

${ }^{22}$ Xie M. W., Gorodetsky R., Micewicz E. D. Marrow-derived stromal cell delivery on fibrin microbeads can correct radiation-induced wound-healing deficits. J Invest Dermatol. 2013. Vol. 133. P. 553-561. DOI 10.1038/jid.2012.326

${ }^{23}$ Chang P., Qu Y., Liu Y. Multi-therapeutic effects of human adipose-derived mesenchymal stem cells on radiation-induced intestinal injury. Cell Death Dis. 2013. DOI 10.1038/cddis.2013.178

Linard C., Busson E., Holler V. Repeated autologous bone marrow-derived mesenchymal stem cell injections improve radiation-induced proctitis in pigs. Stem Cells Transl Med. 2013.Vol. 2. P. 916-927. DOI 10.5966/sctm.2013-0030

${ }^{24}$ Kuova L. V., Konoplyannikov A. G., Pasov V. V. Possibilities for the use of autologous mesenchymal stem cells in the therapy of radiation-induced lung injuries. Bull Exp Biol Med. 2009. Vol. 147. P. 542-546. DOI 10.1007/s10517-009-0538-7

Wang H., Yang Y. F., Zhao L. Hepatocyte growth factor gene-modified mesenchymal stem cells reduce radiation-induced lung injury. Hum Gene Ther. 2013. Vol 24. P. 343-353. DOI 10.1089/hum.2012.177 
radiation burn injury ${ }^{26}$. $\mathrm{Hu}$ et al reported that an appropriate quantity of MSCs promotes the repair of damage in hematopoiesis and immune organs, exhibiting a protective role in mice with acute radiation injury.

In several studies it has demonstrated the regenerative potential of MSCs in different pathological processes. It is important fact that MSCs have ability for homing to injured sites after injections ${ }^{27}$.

High proliferative and differentiation abilities of MSCs and a wide range of produced growth factors and cytokines are in the basis of MSC therapeutic potential. There were anti-apoptotic ${ }^{28}$, anti-oxidative stress $^{29}$, anti-inflammatory ${ }^{30}$ pro-angiogenic ${ }^{31}$ effects of MSCs have been determined.

Our results were consistent with the results from Zheng K. et $\mathrm{al}^{32}$ that showed BM MSCs promoted the growth of granulation tissue and

${ }^{25}$ Lim J. Y., Ra J. C., Shin I. S. Systemic transplantation of human adipose tissuederived mesenchymal stem cells for the regeneration of irradiation-induced salivary gland damage. PLoS One. 2013. DOI 10.1371/journal.pone.0071167

${ }^{26}$ Hao L., Wang J., Zou Z. Transplantation of BMSCs expressing hPDGF-A/hBD2 promotes wound healing in rats with combined radiation-wound injury. Gene Ther. 2009. Vol. 16. P. 34-42. DOI 10.1038/gt.2008.133

${ }^{27}$ Shen F.H., Visger J.M., Balian G. Systemically administered mesenchymal stromal cells transduced with insulin-like growth factor-I localize to a fracture site and potentiate healing. J. Orthop. Trauma. 2002. Vol. 16, № 9. P. 651-659. DOI 10.1097/00005131-200210000-00007

Neuss S., Becher E., Woltje M. Functional expression of HGF and HGF receptor/cmet in adult human mesenchymal stem cells suggests a role in cell mobilization, tissue repair, and wound healing. Stem Cells. 2004. Vol. 22, № 3. P. 405-414. DOI 10.1634/stemcells.22-3-405

${ }^{28}$ Selek O., Buluc L., Muezzinoglu B. Mesenchymal stem cell application improves tendon healing via anti-apoptotic effect (animal study). Acta Orthop. Traumatol. Turc. 2014. Vol 48, № 2. P. 187-195. DOI 10.3944/AOTT.2014.2985

${ }^{29}$ Torrente D., Avila M., Cabezas R. Paracrine factors of human mesenchymal stem cells increase wound closure and reduce reactive oxygen species production in a traumatic brain injury in vitro model. Hum. Exp. Toxicol. 2014. Vol 33, № 7. P. 673-684. DOI 10.1177/0960327113509659

Sukpat S., Isarasena N., Wongphoom J. Vasculoprotective effects of combined endothelial progenitor cells and mesenchymal stem cells in diabetic wound care: their potential role in decreasing wound-oxidative stress. Biomed. Res. Int. 2013. DOI 10.1155/2013/459196

${ }^{30}$ Horton J.A., Hudak K.E., Chung E.J. Mesenchymal stem cells inhibit cutaneous radiation-induced fibrosis by suppressing chronic inflammation. Stem Cells. 2013. Vol. 31, № 10. P. 2231-2241. DOI 10.1002/stem.1483

${ }^{31}$ Wu Y., Chen L., Scott P.G. Mesenchymal stem cells enhance wound healing through differentiation and angiogenesis. Stem Cells. 2007. Vol 25, № 10. P. 2648-2659. DOI 10.1634/stemcells.2007-0226

${ }^{32}$ Zheng K., Wu W., Chen J. Bone marrow mesenchymal stem cell implantation for the treatment of radioactivity-induced acute skin damage in rats. Molecular Medicine Reports. Vol. 2, № 5. P. 7065-7071. DOI 10.3892/mmr.2015.4270 
neovessels, as well as collagen hyperplasia at 6 weeks after irradiation. At 8 weeks after irradiation, epithelialization and increased cutaneous appendages were observed in the BM MSC group, suggesting that BM MSCs can accelerate wound healing, consistent with the above results. TGF- $\beta 1$ is involved in the inflammatory response at the early stages of injury ${ }^{33}$.

It is also involved in fibrosis by promoting the transport of fibronectin and epithelial cells during the process of tissue-repair. SDF-1 is a chemokine involved in the process of stem cell homing ${ }^{34}$ PGE is widely distributed in vivo, among which PGE2 exhibits an important regulatory role in physiological processes, such as inflammatory and anti-inflammatory responses. It was reported, that BM MSCs could prominently reduce the expression of TGF- $\beta 1$ and PGE2, and significantly increase SDF-1 expression in the irradiated rats. It was hypothesized that BM MSCs promote wound healing by inhibiting the expression of PGE2 and TGF- $\beta 1$, reducing local inflammatory reactions and inhibiting fibrosis at the inflammatory reaction stage. During wound repair, BM MSCs can promote the production of SDF-1 by fibroblasts and thereby promote the migration of BM MSCs to the injury site ${ }^{35}$.

It is known, that MSCs isolated from BM are able to adhesion and proliferation on culture plastic. During cultivation at a low seeding dose clonogenic MSCs form fibroblast-like colonies. Clonogenic MSCs give a rise to new subpopulations of MSCs, which can be multiplied multiple times under monolayer culture conditions (during expansion ex vivo) ${ }^{36}$. However long term cultivation leads to aging MSCs and their regenerative effectiveness is lost. Cryopreservation allows preserving MSCs which were expanded for a short period. This makes it possible to obtain the required amount of BM MSCs from early stages of cultivation ex vivo for further

${ }^{33}$ Ueno T., Nakashima Аю, Doi S. Mesenchymal stem cells ameliorate experimental peritoneal fibrosis by suppressing inflammation and inhibiting TGF- $\beta 1$ signaling. Kidney Int. 2013. Vol. 84. P. 297-307. DOI 10.1038/ki.2013.81

${ }^{34} \mathrm{Li}$ Q., Zhang A., Tao C. The role of SDF-1-CXCR4/CXCR7 axis in biological behaviors of adipose tissue-derived mesenchymal stem cells in vitro. Biochem Biophys Res Commun. 2013. Vol. 441. P. 675-680. DOI 10.1016/j.bbrc.2013.10.071

${ }^{35}$ Zhao X., Liu L., Liu D. Progesterone enhances immunoregulatory activity of human mesenchymal stem cells via PGE2 and IL-6. Am J Reprod Immunol. 2012. Vol 68. P. 290-300. DOI 10.1111/j.1600-0897.2012.01163.x

${ }^{36} \mathrm{Hu}$ K. X., Sun Q. Y., Guo M. The radiation protection and therapy effects of mesenchymal stem cells in mice with acute radiation injury. Br. J. Radiol. 2010. Vol. 83, № 985. P. 52-58. DOI 10.1259/bjr/61042310

Liu H., Fan H., Toh S. L. A comparison of rabbit mesenchymal stem cells and anterior cruciate ligament fibroblasts responses on combined silk scaffolds. Biomaterials. 2008. Vol. 29, № 10. P. 1443-1453. DOI 10.1016/j.biomaterials.2007.11.023 
experimental and clinical application. The choice of the conditions of expansion ex vivo and low-temperature preservation of the cultured MSCs is an important condition for successful use in further MSC therapy.

In connection with this in our study paid special attention to analyses of the functional properties of expanded BM MSCs after cryopreservation. In our investigation the methodological approaches of cultivation allowed to estimate clonogenic MSC pool isolated from rat BM in culture. After that stable expansion under culture conditions BM MSCs saved a high proliferative potential with cumulative PDL of 3,14 after 2 passages.

According to applied the method of cryopreservation by slow cooling with the rate $1{ }^{\circ} \mathrm{C} / \mathrm{min}$ to $-70{ }^{\circ} \mathrm{C}$ under $10 \%$ DMSO protection it was saved of $80,8 \%$ of viable expanded BM MSCs. Cryopreserved BM MSCs were able to form colonies, proliferate and to be induced into adipogenic differentiation in culture. The therapeutic potential of cryopreserved BM MSCs was demonstrated at treatment of radiation skin damage in a rat model.

\section{CONCLUSIONS}

The results suggest that local BM MSC injection may be a promising therapeutic approach to improve skin radiation damages. However, the appropriate BM MSC treatment timing, treatment pathway and administration quantity requires further investigation in future studies.

\section{SUMMARY}

The present study aimed to investigate the therapeutic influence of BM MSCs on the healing of acute skin radiation damage in rat model. A rat model of skin radiation damage was established by local irradiation of the right hip skin of rats using the X ray device Faxitron MultiRad 225 (50 Gy, dose rate 7,2 Gy/min). Rat bone marrow MSCs (BM MSCs) were isolated and expanded ex vivo. BM MSCs treatment in rat model was represented as local multipoint injection of $1,5 \times 10^{6} \mathrm{BM}$ MSCs around the damaged skin twice at days 14 and 21 after irradiation. After irradiation, rats were divided into control and BM MSCs - injected groups. The results demonstrated therapeutic effect of BM MSCs on radiation skin damage. In BM MSCs injected group clinical score was significantly 1,3 time milder and the depth and wound size in irradiation area in the BM MSCs group was on 1,7 and 1,9 times decreasing than in the control group. The radiation lesions in skin were not evolving to ulceration and displayed more faster and an important healing at day 45 after BM MSCs injection. The results suggest that local BM MSC injection may be a promising therapeutic approach to improve skin radiation damages. 


\section{REFERENCES}

1. Ryan J. L. Ionizing radiation: the good, the bad, and the ugly. J. Investig. Dermatol. 2007. Vol. 132. P. 985-993. DOI 10.1038/jid.2011.411

2. Haubner F., Ohmann E., Pohl F.Wound healing after radiation therapy: review of the literature. Radiat. Oncol. 2012. Vol. 7. P. 162-189. DOI 10.1186/1748-717X-7-162.

3. Bray F.N., Simmons B.J., Wolfson A.H. Acute and chronic cutaneous reactions to ionizing radiation therapy. Dermatol. Ther. 2016. Vol. 15. P. 185-206. DOI 10.1007/s13555-016-0120-y

4. Ohyama M. Hair follicle bulge: a fascinating reservoir of epithelial stem cells. J. Dermatol. Sci. 2007. Vol. 46. P. 81-89. DOI 10.1016/j.jdermsci.2006.12.002

5. Hill R. P., Rodemann H. P., Hendry J. H. Normal tissue radiobiology: from the laboratory to the clinic. Int J Radiat Oncol Biol Phys. 2001. Vol. 49, № 2. P. 353-365. DOI 10.1016/s0360-3016(00)01484-x

6. Peter R.U. Cutaneous radiation syndrome in multiorgan failure. Br J Radiol Suppl. 2005. Vol. 27. P. 180-184. DOI 10.1259/bjr/56925969

7. Peter R.U., Panizzon R.G., Seegenschmiedt M.H. Diagnosis and treatment of cutaneous radiation injuries. Radiation treatment and radiation reactions in dermatology. 2015. P. 185-188. DOI 10.1007/978-3-66244826-7_15

8. Liubavicuite A., Kaseta V., Vaitcuviene A. Regenerative potential of partially differentiated mesenchymal stromal cells in a mouse model of a full-thickness skin wound. EXCLI J. 2018. Vol. 17. P. 871-888. DOI 10.17179/excli2018-1504

9. Malhotra S., Hu M. S., Marshall C. D. Mesenchymal stromal cellsbased therapeutics for wound healing. Stem Cells Int. 2016. DOI 10.1155/2016/4157934

10. Kolf C.M., Cho E., Tuan R.S. Mesenchymal stromal cells. Biology of adult mesenchymal stem cells: regulation of niche, self-renewal and differentiation. Arthritis Res Ther. 2007. Vol. 9, № 1. P. 204. DOI 10.1186/ar2116

11. Dominici M., Le Blanc K., Muller I. Minimal criteria for defining multipotent mesenchymal stromal cells. The International Society for Cellular Therapy. 2006. Vol. 8, № 4. P. 315-317.

12. Francois S., Mouiseddine M., Allenet-Lepage B. Human mesenchymal stem cells provide protection against radiation-induced liver injury by antioxidative process, vasculature protection, hepatocyte 
differentiation, and trophic effects. Biomed Res Int. 2013. DOI $10.1155 / 2013 / 151679$

13. Hu K.X., Sun Q.Y., Guo M. The radiation protection and therapy effects of mesenchymal stem cells in mice with acute radiation injury. Br. J. Radiol. 2010. Vol. 83. P. 52-58. DOI 10.1259/bjr/61042310

14. Saha S., Bhanja P., Kabarriti R. Bone marrow stromal cell transplantation mitigates radiation-induced gastrointestinal syndrome in mice. PLoS One. 2011. Vol. 6. P. 24072. DOI 10.1371/journal.pone.0024072

15. Abdel-Mageed A.S., Senagore A.J., Pietryga D.W. Intravenous administration of mesenchymal stem cells genetically modified with extracellular superoxide dismutase improves survival in irradiated mice. Blood. 2009. Vol. 113, № 5. P. 1201-3. DOI 10.1182/blood-2008-07170936.

16. Lataillade J.J., Douce C., Bey E. New approach to radiation burn treatment by dosimetry-guided surgery combined with autologous mesenchymal stem cell therapy. Regen. Med. 2007. Vol. 2. P. 785-794.

17. Eaton E. B., Varney T. R. Mesenchymal stem cell therapy for acute radiation syndrome: innovative medical approaches in military medicine. Mil. Med. Res. 2015. Vol. 2. P. 2-19. DOI 10.1186/s40779-014-0027-9

18. Nakagawa H., Akita S., Fukui M. Human mesenchymal stem ce lls successfully improve skin-substitute wound healing. Br J Dermatol. 2005. Vol 153. P. 29-36. DOI 10.1111/j.1365-2133.2005.06554.x

19. Kim J.-W., Lee J.-H., Lyo Y. S. The effects of topical mesenchymal stem cell transplantation in canine experimental cutaneous wounds. Vet. Dermatol. 2013. Vol. 24. P. 242-253. DOI 10.1111/vde.12011

20. François S., Bensidhoum M., Mouiseddine M. Local irradiation induces not only homing of human Mesenchymal stem cells (hMSC) at exposed sites but promotes their widespread engraftment to multiple organs: a study of their quantitative distribution following irradiation damages. Stem Cells. 2005. Vol. 24, № 4, P. 1020-1029. DOI 10.1634/stemcells.2005-0260

21. Epperly M.W., Guo H., Gretton J.E. Bone marrow origin of myofibroblasts in irradiation pulmonary fibrosis. Am J Respir Cell Mol Biol. 2003. Vol. 9, № 2. P. 213-224. DOI 10.1165/rcmb.2002-0069OC

22. Rolfe K.J., Irvine L.M., Grobbelaar A.O. Differential gene expressionin response to transforming growth factor-beta 1 by fetal and posnata1 dermal fibroblasts. Wound Repair Regen. 2007. Vol 15. P. 897-906. DOI 10.1111/j.1524-475X.2007.00314.x 
23. Millar W. T., Van Den Aardweg G. J., Hopewell J. W. Repair kinetics in pig epidermis: An analysis based on two separate rates of repair. Int $J$ Radiat Biol. 1996. Vol. 69. P. 123-140. DOI 10.1080/095530096146255

24. Agay D., Scherthan H., Forcheron F. Multipotent mesenchymal stem cell grafting to treat cutaneous radiation syndrome: Development of a new minipig model. Exp Hematol. 2010. Vol. 38. P. 945-956. DOI 10.1016/j.exphem.2010.06.008

25. Deng W., Han Q., Liao L. Engrafted bone marrow-derived flk- (1+) mesenchymal stem cells regenerate skin tissue. Tissue Eng. 2005. Vol. 11. P. 110-119. DOI 10.1089/ten.2005.11.110

26. Moroz B.B., Onizhshenko N.A., Lebedev V.G. The influence of multi-potent mesenchymal stromal cells of bone marrow on process of local radiation injury in rats after local beta-irradiation. Radiats Biol Radioecol. 2009. Vol. 49. P. 688-693.

27. Xie M.W., Gorodetsky R., Micewicz E.D. Marrow-derived stromal cell delivery on fibrin microbeads can correct radiation-induced woundhealing deficits. J Invest Dermatol. 2013. Vol. 133. P. 553-561. DOI 10.1038/jid.2012.326

28. Chang P., Qu Y., Liu Y. Multi-therapeutic effects of human adiposederived mesenchymal stem cells on radiation-induced intestinal injury. Cell Death Dis. 2013. DOI 10.1038/cddis.2013.178.

29. Linard C., Busson E., Holler V. Repeated autologous bone marrowderived mesenchymal stem cell injections improve radiation-induced proctitis in pigs. Stem Cells Transl Med. 2013. Vol. 2. P. 916-927. DOI 10.5966/sctm.2013-0030

30. Kuova L.V., Konoplyannikov A.G., Pasov V.V. Possibilities for the use of autologous mesenchymal stem cells in the therapy of radiationinduced lung injuries. Bull Exp Biol Med. 2009. Vol. 147. P. 542-546. DOI 10.1007/s10517-009-0538-7.

31. Wang H., Yang Y.F., Zhao L. Hepatocyte growth factor genemodified mesenchymal stem cells reduce radiation-induced lung injury. Hum Gene Ther. 2013. Vol. 24. P. 343-353. DOI 10.1089/hum.2012.177.

32. Lim J.Y., Ra J.C., Shin I.S. Systemic transplantation of human adipose tissue-derived mesenchymal stem cells for the regeneration of irradiation-induced salivary gland damage. PLoS One. 2013. DOI 10.1371/journal.pone.0071167.

33. Hao L., Wang J., Zou Z. Transplantation of BMSCs expressing hPDGF-A/hBD2 promotes wound healing in rats with combined radiation- 
wound injury. Gene Ther. 2009. Vol. 16. P 34-42. DOI 10.1038/gt.2008.133.

34. Shen F.H., Visger J.M., Balian G. Systemically administered mesenchymal stromal cells transduced with insulin-like growth factor-I localize to a fracture site and potentiate healing. J. Orthop. Trauma. 2002. Vol. 16, № 9. P. 651-659. DOI 10.1097/00005131-200210000-00007.

35. Neuss S., Becher E., Woltje M. Functional expression of HGF and HGF receptor/c-met in adult human mesenchymal stem cells suggests a role in cell mobilization, tissue repair, and wound healing. Stem Cells. 2004. Vol. 22, № 3. P. 405-414. DOI 10.1634/stemcells.22-3-405

36. Selek O., Buluc L., Muezzinoglu B. Mesenchymal stem cell application improves tendon healing via anti-apoptotic effect (animal study). Acta Orthop. Traumatol. Turc. 2014. Vol 48, № 2. P. 187-195. DOI 10.3944/AOTT.2014.2985

37. Torrente D., Avila M., Cabezas R. Paracrine factors of human mesenchymal stem cells increase wound closure and reduce reactive oxygen species production in a traumatic brain injury in vitro model. Hum. Exp. Toxicol. 2014. Vol 33, № 7. P. 673-684. DOI 10.1177/0960327113509659

38. Sukpat S., Isarasena N., Wongphoom J. Vasculoprotective effects of combined endothelial progenitor cells and mesenchymal stem cells in diabetic wound care: their potential role in decreasing wound-oxidative stress. Biomed. Res. Int. 2013. DOI 10.1155/2013/459196

39. Horton J.A., Hudak K.E., Chung E.J. Mesenchymal stem cells inhibit cutaneous radiation-induced fibrosis by suppressing chronic inflammation. Stem Cells. 2013. Vol. 31, № 10. P. 2231-2241. DOI 10.1002/stem.1483

40. Wu Y., Chen L., Scott P.G. Mesenchymal stem cells enhance wound healing through differentiation and angiogenesis. Stem Cells. 2007. Vol. 25, № 10. P. 2648-2659. DOI 10.1634/stemcells.2007-0226

41.Zheng K., Wu W., Chen J. Bone marrow mesenchymal stem cell implantation for the treatment of radioactivity-induced acute skin damage in rats. Molecular Medicine Reports. Vol. 2, № 5. P. 7065-7071. DOI 10.3892/mmr.2015.4270

42. Ueno T., Nakashima Aю, Doi S. Mesenchymal stem cells ameliorate experimental peritoneal fibrosis by suppressing inflammation and inhibiting TGF- $\beta 1$ signaling. Kidney Int. 2013. Vol. 84. P. 297-307. DOI 10.1038/ki.2013.81

43. Li Q., Zhang A., Tao C. The role of SDF-1-CXCR4/CXCR7 axis in biological behaviors of adipose tissue-derived mesenchymal stem cells in 
vitro. Biochem Biophys Res Commun. 2013. Vol. 441. P. 675-680. DOI 10.1016/j.bbrc.2013.10.071

44. Russell K. C., Lacey M. R., Gilliam J. K. Clonal Analysis of the Proliferation Potential of Human Bone Marrow Mesenchymal Stem Cells as a Function of Potency. Biotechnol Bioeng. 2011. Vol. 108, № 11. P. 2716-2726. DOI 10.1002/bit.23193

45. Hu K. X., Sun Q. Y., Guo M. The radiation protection and therapy effects of mesenchymal stem cells in mice with acute radiation injury. Br. J. Radiol. 2010. Vol. 83, № 985. P. 52-58. DOI 10.1259/bjr/61042310

46. Liu H., Fan H., Toh S. L. A comparison of rabbit mesenchymal stem cells and anterior cruciate ligament fibroblasts responses on combined silk scaffolds. Biomaterials. 2008. Vol. 29, № 10. P. 1443-1453. DOI 10.1016/j.biomaterials.2007.11.023

\section{Information about authors: Uzlenkova N. Ye., Ph.D.,} Head of Laboratory of Antiradiation Drugs and Cell Technologies

Grigoriev Institute for Medical Radiology of the National Academy of Medical Sciences of Ukraine

82, Pushkinskay str., Kharkiv, 61024, Ukraine

Skorobogatova N. H., Ph.D., Research Scientist Laboratory of Antiradiation Drugs and Cell Technologies

Grigoriev Institute for Medical Radiology of the National Academy of Medical Sciences of Ukraine 82, Pushkinskay str., Kharkiv, 61024, Ukraine

Kryvko A. I., Ph.D. Student of Department of Biochemistry V. N. Karazin Kharkiv National University 4, Svobody Sq., Kharkiv, 61022, Ukraine 